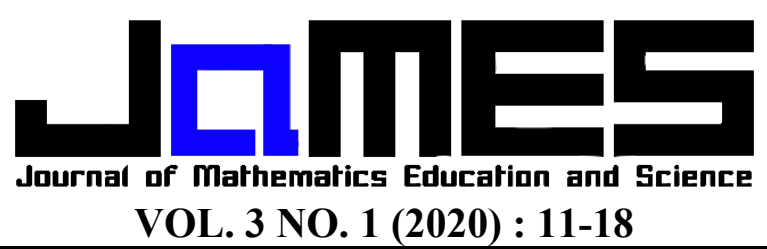

\title{
PERBANDINGAN STRATEGI BELAJAR AKTIF TIPE JOEPARDY REVIEV DENGAN TIPE HOLLYWOOD SQUARES REVIEW DENGAN PENDEKATAN VISUAL THINKING TERHADAP PEMAHAMAN KONSEP MATEMATIKA
}

\author{
Ria Indriani ${ }^{1}$, Imam Syafe'i ${ }^{2}$, Siska Andriani ${ }^{3}$ \\ Universitas Islam Negeri Raden Intan Lampung, riaindriani1825@gmail.com ${ }^{1}$ \\ Universitas Islam Negeri Raden Intan Lampung, imamsyafei@radenintan.ac.id ${ }^{2}$ \\ Universitas Islam Negeri Raden Intan Lampung, siskaandriani@radenintan.ac.id ${ }^{3}$ \\ Received : 25 April 2019, Revised : 23 April 2020, Accepted : 24 April 2020 \\ (C) Mathematics Education Unugiri 2020
}

\begin{abstract}
This study aims to compare the Active Learning Type Type Joepardy Reviev with the Type of Hollywood Squares Review with a Visual Thinking Approach to the ability to understand the mathematical concepts of students. This type of research is quantitative research. Data collection techniques used are essay tests, questionnaires and interviews. The data analysis technique used is hypothesis testing using 2 way ANAVA. Based on the results of the study, there were differences in the ability to understand the mathematical concepts of students by using the active learning type Jeopardy Review and Hollywood Squares Review strategies using the Visual Thinking approach. The Hollywood Squares Review active learning strategy with the Visual Thinking approach provides a better influence on students' ability to understand mathematical concepts. This can be seen from the average value of the mathematics concept comprehension test results of the experimental class 2 students using the Hollywood Squares Review type active learning strategy with Visual Thinking approach of 78,346 higher than the experimental class 1 using the Jeopardy Review type active learning strategy with the Visual Thinking approach is 77,500.
\end{abstract}

Keywords: Active Strategy Type Joepardy Reviev; Active Strategy Type Type Hollywood Squares Review; Visual Thinking Approach; ability to understand mathematical concepts

\begin{abstract}
Abstrak
Penelitian ini bertujuan untuk membandingkan Strategi Belajar Aktif Tipe Joepardy Reviev Dengan Tipe Hollywood Squares Review Dengan Pendekatan Visual Thinking terhadap kemampuan pemahaman konsep matematis peserta didik. Jenis penelitian ini adalah penelitian kuantitatif. Tehnik pengumpulan data yang digunakan adalah tes essay, angket dan wawancara. Tehnik analisis data yang digunakan adalah uji hipotesis dengan menggunakan anava 2 jalan. Berdasarkan hasil penelitian diperoleh terdapat perbedaan kemampuan pemahaman konsep matematika peserta didik dengan menggunakan strategi pembelajaran aktif tipe Jeopardy Review dan Hollywood Squares Review dengan pendekatan Visual Thinking. Strategi pembelajaran aktif tipe Hollywood Squares Review dengan pendekatan Visual Thinking memberikan pengaruh yang lebih baik terhadap kemampuan pemahaman konsep matematika peserta didik. Hal ini terlihat dari nilai rata-rata hasil tes kemampuan pemahaman konsep matematika peserta didik kelas eksperimen 2 yang menggunakan strategi pembelajaran aktif tipe Hollywood Squares Review dengan pendekatan Visual Thinking sebesar 78,346 lebih tinggi dibandingkan dengan kelas eksperimen 1 yang menggunakan strategi pebelajaran aktif tipe Jeopardy Review dengan pendekatan Visual Thinking sebesar 77,500 .
\end{abstract}

Kata kunci: Strategi aktif Tipe Joepardy Reviev; Strategi aktif Tipe Tipe Hollywood Squares Review; Pendekatan Visual Thinking; kemampuan pemahaman konsep matematis 


\section{Pendahuluan}

Salah satu tujuan penting dalam pembelajaran matematika adalah dengan memahami konsep matematis. Melalui pemahaman konsep, peserta didik lebih mengerti akan pembelajaran yang dipelajari [1]. Peserta didik yang memiliki pemahaman konsep matematis yang baik akan lebih mudah untuk menyelesaikan variansi soal yang berbeda. Hal ini sejalan dengan tujuan pembelajaran pada tingkat sekolah dasar maupun menengah dimana peserta didik dapat memahami suatu konsep matematis dengan baik [2].

Konsep dalam belajar matematika adalah suatu hal yang sangat mendasar. Kesalahan konsep yang telah terjadi pada diri peserta didik akan mengganggu efektifitas belajar serta mengganggu pemikiran peserta didik dalam menerima pengetahuan berikutnya [3]. Maka dari itu perlu adanya suatu pemahaman konsep matematis yang baik yang dimulai dari pemahaman konsep yang mudah sampai pemahaman konsep yang sulit [4]. Namun kemampuan pemahaman konsep matematis peserta didik masih belum menggembirakan. Pada beberapa penelitian yang telah dilakukan yang menyatakan bahwa kemampuan pemecahanan masalah matematis peserta didik masih rendah. Seperti yang diungkapkan oleh putra dalam penelitiannya yang dilakukan di SMP Negeri 1 Pematang bahwa kemampuan pemecahan masalah matematis peserta didik masih tergolong rendah [5]. Selain itu menurut Kamid dan kawan-kawan dalam penelitiannya mengungkapkankan Kamid, Anggereini, \& Muhtadin (2018) rata-rata hasil belajar peserta didik masih sangat rendah, tak dapat dipungkiri hal ini karena kurangnya kemampuan pemahaman konsep peserta didik.

Sama halnya yang terjadi di SMPN 3 Palas, berdasarkan hasil observasi dperoleh bahwa rata-rata hasil belajar matematika peserta didik masih sangat rendah, kemampuan dalam pemahaman materi mengenai konsep-konsep matematika juga sangat kurang. Seperti yang telah diungkakan oleh guru bahwa peserta didik cenderung pasif dalam belajar matematika, sehingga matematika adalah pelajaran yang sulit dalam anggapan peserta didik tidak bisa dihindarkan. Beberapa penelitian telah meakukan penlitian mengungkapakan bahwa rendahnya kemampuan pemahaman konsep matematis peserta didik diduga dipengaruhi oleh penerapan model pembelajaran yang digunakan oleh guru [7]. Pemilihan model pembelajaran yang tepat akan membantu peserta didik dalam memahami materi dengan lebih baik [8], [9]. Sejalan dengan yang diungkapkan oleh Yuliasari [10] bahwa untuk mempermudah peserta didik dalam menguasai kemampuan pemahaman konsep matematis peserta didik dalam proses belajar dibutuhkan model pembelajaran yang tepat dan sesuai dengan materi pembelajaran. Berdasarkan hal ini maka dapat disimpulkan rendahnya kemampuan pemahaman konsep peserta didik dapat diatasi dengan strategi pembelajaran aktif.

Strategi pembelajaran aktif yang akan digunakan dalam penelitian ini adalah strategi pembelajaran aktif tipe Joepardy Review Dengan Tipe Hollywood Squares Review. Menurut Siberman dalam penelitian Nursida [11] Strategi pembelajaran aktif tipe Jeopardy Review ini menitik beratkan pada kerjasama tim dan strategi ini merupakan suatu kegiatan 
belajar bersama dimana guru membagi siswa kedalam beberapa kelompok kemudian membuat pertanyaan-pertanyaan sesuai topiktopik yang diajarkan. Sehingga strategi akan mampu membuat peserta didik akan lebih aktif dan dapat meningkatkan kemampuan pemahaman konsep peserta didik. Merujuk hasil penelitian oleh Felda Felda, mukhni, \& khairudin (2014) dari data hasil belajar diberikan tes dan analisis uji hipotesis mendapatkan nilai thitung $=2,11>$ ttabel $=$ 1,68 pada tingkat kepercayaan $95 \%$, hal ini berarti hasil belajar matematika peserta didik dengan menerapkan strategi pembelajaran aktif tipe Jeopardy Review lebih baik dari hasil belajar matematika peserta didik yang menerapkan pembelajaran konvensional. Selain itu rujukan dari penelitian oleh Elisa dan Syafmen [13] dengan penelitian membandingkan strategi belajar aktif tipe jeopardy review dan who wants to be a millioner diperoleh hasil Persentase jumlah peserta didik yang tuntas setelah diajarkan dengan strategi belajar aktif Joepardy Review juga meningkat yaitu menjadi 84,4 sedangkan persentase peserta didik dengan perlakuan strategi who wants to be a millioner yang tuntas mencapai KKM sebesar 80,43\%. Berdasarkan data diatas dpat disimpulkan bahwa hasil belajar matematika peserta didik yang diajarkan dengan menggunakan strategi belajar aktif tipe Joepardy Review lebih baik jika dibandingkan dengan hasil belajar matematika peserta didik yang diajarkan dengan menggunakan strategi belajar aktif tipe Who Wants to be a Millionaire.

Disamping itu penulis juga akan melihat sebuah pengaruh dari strategi pembelajaran aktif Tipe Hollywood Squares Review. Menurut Maedani [14] dalam hasil penelitiannya diperoleh bahwa Rata-rata hasil belajar kelas menggunakan strategi pembelajaran aktif Hollywood Squares yaitu 78,8 . Sedangkan Rata-rata hasil belajar kelas menggunakan pembelajaran konvensional yaitu 74,06. Hal ini berarti strategi pembelajaran aktif Hollywood Squares lebih baik dari pada pembelajaran konvensional terutamadalam meningkatkan aktivitas belajar siswa. Sama halnya dengan hasil penelitian oleh Berdasarkan hasil uji analisis data nilai signifikansi $0,045<0,05$, artinya penggunaan strategi pembelajaran Hollywood Squares Review dapat meningkatkan prestasi belajar dan kemampuan pemahaman konsep peserta didik. Berdasarkan tujuan dan hasil penelitian yang telah dipaparkan diatas, kedua model ini sama halnya dapa meningkatkan kemampuan penalaran matematis dan motivasi belajar peserta didik. Namun perbedaannya, strategi type Joepardy Review lebih ditekankan pada belajar bersama atau kerjasama dalam tim. Sedangakan trategi aktif type Hollywood Squares lebih ditekankan pada individual atau dari pemikiran sendiri. Sehingga penulis ingin melakukan penelitian dengan tujuan melihat perbedaan strategi aktif type Joepardy Review Dan type Hollywood Squares terhadap kemampuan pemahaman konsep matematis.

Agar lebih efektif kedua strategi ini akan diterapkan pendekatan visual thinking. Karena visual thingking adalah proses intelektual intuitif dan ide imajinasi visual, baik dalam pencitraan mental atau melalui gambar (Brasseur,Goldsmchmidt,Laseau) menyatakan mengandalkan proses berpikir bahasa gambar visual, bentuk, pola, tekstur, symbol. Penggunan pendekatan ini selain membantu penerapan kedua strategi aktif 
tersebut juga sebagai keterbaharuan penulis dalam penelitian ini.

\section{Metode Penelitian}

Metode penelitian yang digunakan pada penelitian ini adalah menggunakan penelitian eksperimen karena penulis akan mencari perbedaan treatment (perlakuan) tertentu dengan desain penelitian posttest-only control design sehingga jenis penelitian ini adalah penelitian kuantitatif. Variabel bebas dalam penelitian ini yaitu strategi belajar aktif tipe Joepardy Review dengan pendekatan Visual Thinking $\left(\mathrm{X}_{1}\right)$ dan strategi belajar aktif tipe Hollywood Squares Review dengan pendekatan Visual Thinking $\left(\mathrm{X}_{2}\right)$. Sedangkan yang menjadi varibel terikatnya adalah kemampuan pemahaman konsep matematis. Populasi dalam penelitian ini adalah seluruh peserta didik kelas VIII semester ganjil SMP Negeri 3 Palas yang terdiri dari tiga kelas dengan jumlah 94 peserta didik. Teknik pengambilan sampel yang digunakan adalah teknik purposive sampling. Kelas yang akan digunakan adalah kelas eksperimen1, kelas eksperimen2 dan kelas kontrol. Adapun teknik pengumpulan data yang digunakan tes, wawancara dan observasi. Sedangkan teknik pengolahan data yang digunakan adalah uji hipotesis dengan uji anava 1 arah. Adapun hipotesis yang digunakan adalah

$\mathrm{H}_{0}: \mu_{1} \leq \mu_{2} \quad$ kemampuan pemahaman konsep matematika peserta didik tidak meningkat melalui strategi pembelajaran aktif tipe Jeopardy Review dan Hollywood Squares Review dengan pendekatan Visual Thinking dari pada yang menggunakan strategi konvesional dengan pendekatan Visual Thinking.

$\mathrm{H}_{1}: \mu_{1}>\mu_{2} \quad$ kemampuan pemahaman konsep matematika peserta didik meningkat melalui strategi pembelajaran aktif tipe Jeopardy Review dan Hollywood Squares Review dengan pendekatan Visual
Thinking dari pada yang menggunakan strategi konvensional dengan pendekatan Visual Thinking.

Pengujian dilakukan dengan taraf signifikasi yang digunakan dalam penelitian ini adalah $\alpha$ $=0,05$ dengan Kriteria pengujian Terima $\mathrm{H}_{0}$, jika $F_{\text {hitung }}<F_{\text {tabel }}$ dan Tolak $\mathrm{H}_{0}$, jika $F_{\text {hitung }}$ $\geq \mathrm{F}_{\text {tabel. }}$

\section{Hasil dan Pembahasan}

Setelah hasil tes kemampuan pemahaman konsep peserta didik kelas eksperimen 1, eksperimen 2 dan kelas control sudah terkumpul dengan baik, maka diperoleh deskripsi amatan sebagai berikut:

Tabel 1. Deskriptif Data Posttest Kemampuan Pemahman Konsep Matematika Peserta Didik

\begin{tabular}{|c|c|c|c|c|c|c|c|}
\hline \multirow[t]{2}{*}{ Kel. } & \multirow[t]{2}{*}{$\mathrm{N}$} & \multirow{2}{*}{$\begin{array}{c}X_{\mathrm{ma}} \\
\mathrm{x}\end{array}$} & \multirow{2}{*}{$\underset{\mathrm{n}}{\mathrm{X}_{\mathrm{mi}}}$} & \multicolumn{3}{|c|}{$\begin{array}{c}\text { Ukuran Tendesi } \\
\text { Sentral }\end{array}$} & \multirow{2}{*}{$\begin{array}{c}\text { Ukuran } \\
\text { Variansi } \\
\mathrm{S}\end{array}$} \\
\hline & & & & $\overline{\bar{X}}$ & $\mathrm{M}_{\mathrm{o}}$ & $\mathrm{M}_{\mathrm{e}}$ & \\
\hline 1 & 26 & 87 & 57 & 77,500 & 83 & 77 & 6,384 \\
\hline 2 & 26 & 92 & 62 & 78,962 & 87 & 80 & 7,164 \\
\hline $\begin{array}{l}\text { Kon } \\
\text { trol }\end{array}$ & 24 & 85 & 55 & 72,833 & 78 & $\begin{array}{c}73 \\
5\end{array}$ & 7,275 \\
\hline
\end{tabular}

Berdasarkan Tabel 1. diperoleh hasil tes yang diberikan kepada kelas eksperimen 1 dengan strategi pembelajaran aktif tipe Jeopardy Review dengan pendekatan Visual Thinking diperoleh rata-rata yaitu 77,500 dan simpangan baku (S) yaitu 6,384 dan kelas eksperimen 2 dengan strategi pembelajaran aktif tipe Hollywood Squares Review dengan pendekatan Visual Thinking diperoleh ratarata yaitu 78,962 dan simpangan baku (S) yaitu 7,164 sedangkan hasil tes kelas kontrol dengan menggunakan strategi pembelajran konvensional dengan pendekatan Visual Thinking memperoleh rata-rata yaitu 72,833 simpangan baku (S) yaitu 7,275. Sehungga dapat disimpulkan bahwa rata-rata kemampuan pemahaman konsep matematika peserta didik kelas eksperimen 1 dan kelas eksperimen 2 lebih besar dibandingkan kemampuan pemahaman konsep matematika kelas kontrol. 
Setelah semua data tersebut terkumpul, maka akan digunakan untuk uji hipotesis dengan menggunakan uji anava 1 jalan. Namun sebelum uji hipotesis dilakukan perlu adanya dilakukan uji prasyarat hipotesis dengan menggunakan uji normalitas dan uji homogenitas terlebih dahulu. Jika data tidak berdistribusi normal dan tidak berasal dari variansi yang sama maka uji hipotesis dengan anava 1 jalan akan diganti dengan uji non parametric. Data dikatakan normal jika $L_{\text {hitung }}$ $\leq \mathrm{L}_{\text {tabel }}$ dan dikatakan homogeny jika $\chi^{2}{ }_{\text {hitung }}$ $\leq \chi^{2}$ tabel. Adapun hasil uji normalitas dapat dilihat pada Tabel 2 .

Tabel 2. Hasil uji normalitas kemampuan pemahaman konsep matematis

\begin{tabular}{lccc}
\hline \multicolumn{1}{c}{ Kelompok } & Lhitung & L tabel & Keputusan Uji \\
\hline Eksperimen 1 & 0,164 & 0,173 & Normal \\
Eksperimen 2 & 0,065 & 0,173 & Normal \\
Kontrol & 0,079 & 0,173 & Normal \\
\hline
\end{tabular}

Berdasarkan Tabel 2. Hasil uji normalitas pada kelas eksperimen 1 diperoleh $\mathrm{L}_{\text {hitung }}=0,164$ dan $\mathrm{L}_{\text {tabel }}=0,173$ dengan keputusan uji $\mathrm{H}_{0}$ diterima. Pada kelas eksperimen 2 diperoleh $\mathrm{L}_{\text {hitung }}=0,065$ dan $\mathrm{L}_{\text {tabel }}=0,173$ dengan keputusan uji $\mathrm{H}_{0}$ diterima. Sedangkan kelas control kelas diperoleh $\mathrm{L}_{\text {hitung }}=0,079$ dan $\mathrm{L}_{\text {tabel }}=0,173$ dengan keputusan uji $\mathrm{H}_{0}$ diterima. Berdasarkan data tersebut maka didapat pada masing-masing kelas bahwa $\mathrm{L}_{\text {hitung }} \leq \mathrm{L}_{\text {tabel }}$ yang berarti disimpulkan semua data berdistribusi normal. Setelah data diketahui berdistribusi normal maka selanjutnya dilakukan uji homogenitas. Hasil uji homogenitas dapat dilihat pada Tabel 3.

Tabel 3. Hasil uji homogenitas kemampuan pemahaman konsep matematis

\begin{tabular}{lllll}
\multicolumn{1}{c}{ Kelompok } & $\mathrm{N}$ & $\chi^{2}{ }_{\text {hitung }}$ & $\chi^{2}$ tabel & Kesimpulan \\
\hline Eksperimen 1 & 26 & & & \\
Eksperimen 2 & 26 & 0,423 & 5,991 & Homogen \\
Kontrol & 24 & & & \\
\hline
\end{tabular}

Berdasarkan tabel 3 diatas diperoleh $\chi_{\text {hitung }}^{2}=0,423$ dan $\chi_{\text {tabel }}^{2}=5,991$. Terlihat bahwa $\chi^{2}$ hitung $\leq \chi^{2}$ tabel maka dapat disimpulkan bahwa $\mathrm{H}_{0}$ diterima dan sampel berasal dari populasi yang homogen. Setelah data yang diperoleh berdistribusi normal dan data berasal dari variansi yang sama, maka selanjutnya akan dilakukan uji hipotesis dengan menggunakan uji anava 1 jalan sel tak sama. Uji hipotesis ini digunakan karena terdapatnya dua variabel bebas (strategi pembelajaran aktif tipe Jeopardy Review dan Hollywood Squares Review dengan pendekatan Visual Thinking) dan satu variabel terikat (kemampuan pemahaman konsep matematika) dimana setiap sel nya berbeda. Hasil uji anava 1 jalan dapat dilihat pada Tabel 4.

Tabel 4. Uji anava 1 jalan kemampuan pemahaman konsep matematis

\begin{tabular}{lccc}
\hline \multicolumn{1}{c}{ Kelompok } & $F_{\text {hitung }}$ & $\mathrm{F}_{\text {tabel }}$ & Kesimpulan \\
\hline Eksperimen 1 & & & \\
Eksperimen 2 & 5,224 & 3,150 & $\mathrm{H}_{0}$ ditolak \\
Kontrol & & & \\
\hline
\end{tabular}

Berdasarkan uji hipotesis posttest kemampuan pemahaman konsep matematika pada materi bangun ruang sisi datar dapat dilihat bahwa $F_{\text {hitung }}=5,224>F_{\text {tabel }}=3,150$ ini pada taraf signifikasi $\alpha=0,005 \mathrm{H}_{0}$ ditolak. Dengan demikian dapat disimpulkan bahwa terdapat perbedaan penerapan antara ketiga strategi pembelajaran tersebut dalam meningkatkan kemampuan pemahaman konsep matematika peserta didik. Karena ada perbedaan antara ketiga kelas, maka perlu dilakukan uji lanjut yaitu uji komparasi ganda dengan menggunakan uji schuffee'. Uji lanjut ini dilakukan untuk melihat pengaruh mana yang lebih baik dari ketiga kelas. Adapun hasil uji komparasi ganda dapat dilihat pada Tabel berikut:

Tabel 5. Rata-rata Marginal

\begin{tabular}{lc}
\hline \multicolumn{1}{c}{ Strategi Pembelajaran } & Rataan Marginal \\
\hline Jeopardy Review & 77,500 \\
Hollywood Squares Review & 78,962 \\
Konvensional & 72,833 \\
\hline
\end{tabular}


Tabel 6. Rangkuman Hasil Uji Komparasi Ganda

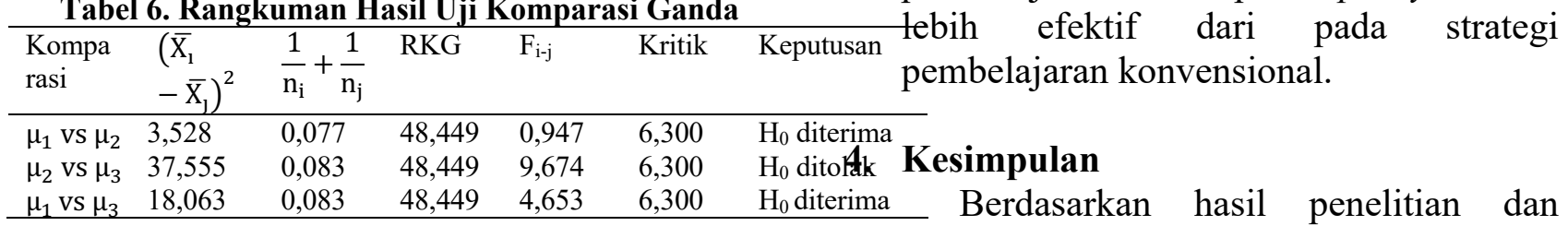

Berdasarkan data diatas hasil uji komparasi ganda dengan menggunakan metode schuffee' maka dapat disimpulkan sebagai berikut:

a. Kemampuan pemahaman konsep matematika dengan perlakuan strategi pembelajaran aktif tipe Jeopardy Review dengan pendekatan Visual Thinking tidak terdapat perbedaan yang signifikan dengan kemampuan pemahaman konsep matematika dengan perlakuan strategi pembelajaran aktif tipe Hollywood Squares Review dengan pendekatan Visual Thinking. Berdasarkan nilai ratarata marginal strategi pembelajaran aktif tipe Jeopardy Review dengan Hollywood Squares Review pada rataan marginal diketahui bahwa strategi pembelajaran Hollywood Squares Review lebih efektif dari pada strategi pembelajaran aktif tipe Jeopardy Review.

b. Kemampuan pemahaman konsep matematika dengan perlakuan strategi pembelajaran aktif tipe Hollywood Squares Review tidak sama dengan kemampuan pemahaman konsep matematika dengan perlakuan strategi pembelajaran konvensional. Pada rataan marginal dapat dilihat bahwa strategi pembelajaran aktif tipe Hollywood squares Review lebih efektif dari pada strategi pembelajaran konvensional.

c. Kemampuan pemahaman konsep matematika dengan perlakuan strategi pembelajaran aktif tipe Jeopardy Review tidak terdapat perbedaan yang signifikan dengan kemampuan pemahaman konsep matematika dengan perlakuan strategi pembelajaran konvensional. Berdasarkan nilai rata-rata marginal pada rataan marginal terlihat bahwa strategi pembelajaran aktif tipe Jeopardy Review lebih efektif dari pada strategi pembahasan yang telah dilakukan dapat disimpulkan bahwa terdapat perbedaan kemampuan pemahaman konsep matematika peserta didik dengan menggunakan strategi pembelajaran aktif tipe Jeopardy Review dan Hollywood Squares Review dengan pendekatan Visual Thinking. Strategi pembelajaran aktif tipe Hollywood Squares Review dengan pendekatan Visual Thinking memberikan pengaruh yang lebih baik terhadap kemampuan pemahaman konsep matematika peserta didik. Hal ini terlihat dari nilai rata-rata hasil tes kemampuan pemahaman konsep matematika peserta didik kelas eksperimen 2 yang menggunakan strategi pembelajaran aktif tipe Hollywood Squares Review dengan pendekatan Visual Thinking sebesar 78,346 lebih tinggi dibandingkan dengan kelas eksperimen 1 yang menggunakan strategi pebelajaran aktif tipe Jeopardy Review dengan pendekatan Visual Thinking sebesar 77,500.

Berdasarkan kesimpulan yang diperoleh disarankan agar pendidik hendaknya dapat menggunakan strategi pembelajaran aktif yang berinovasi agar tidak terjadi kejenuhan dalam proses pembelajaran. Pendidik diharapkan lebih kreatif dalam memilih strategi pembelajaran aktif dalam proses pembelajaran seperti strategi pembelajaran aktif tipe Hollywood Squares Review sehingga kemampuan pemahaman konsep matematika peserta didik dalam proses pembelajaran lebih baik kedepannya. Peserta didik seharusnya tidak perlu merasa ragu dan takut untuk mencoba menuangkan ide-ide kreatif yang dimiliki serta lebih aktif menumbuhkan sikap positif seperti menumbuhkan rasa percaya diri dan rasa 
ingin tahu dalam pembelajaran matematika. Semoga apa yang diteliti dapat dilanjutkan oleh peneliti lain dengan penelitian yang lebih luas dan apa yang diteliti dapat memberikan manfaat dan sumbangan pemikiran bagi pendidik pada umumnya dan peneliti pada khususnya

\section{Referensi}

[1] S. W. Sudarman dan I. Vahlia, "Efektifitas Penggunaan Metode Pembelajaran Quantum Learning terhadap Kemampuan Pemahaman Konsep Matematis Mahasiswa," AlJabar J. Pendidik. Mat., vol. 7, no. 2, hlm. 275-282, 2016.

[2] D. D. Pratiwi, "Pembelajaran Learning Cycle 5E berbantuan Geogebra terhadap Kemampuan Pemahaman Konsep Matematis," Al-Jabar J. Pendidik. Mat., vol. 7, no. 2, hlm. 191-202, 2016.

[3] L. Sukariasih, "Penggunaan Strategi Konflik Kognitif Untuk Mengurangi Miskonsepsi Siswa pada Materi Pokok Gerak Lurus," J. Apl. Fis., vol. 12, no. 2, 2016.

[4] Martunis, M. Ikhsan, dan S. Rizal, "MENINGKATKAN KEMAMPUAN PEMAHAMAN DAN KOMUNIKASI MATEMATIS SISWA SEKOLAH MENENGAH ATAS MELALUI MODEL PEMBELAJARAN GENERATIF," J. Didakt. Mat., vol. 1, no. 2, Sep 2014.

[5] R. Ramadhani, "Peningkatan Kemampuan Pemahaman Konsep Dan Kemampuan Pemecahan Masalah Matematika Siswa SMA Melalui Guided Discovery Learning Berbantuan Autograph," J. Penelit. Dan Pembelajaran Mat., vol. 10, no. 2, 2017.

[6] K. Kamid, E. Anggereini, dan M. Muhtadin, "PENERAPAN MODEL PROBLEM BASED LEARNING UNTUK MENINGKATKAN PEMAHAMAN KONSEP
MATEMATIKA DITINJAU DARI MULTIPLE INTELLIGENCES SISWA," AKSIOMA J. Program Studi Pendidik. Mat., vol. 7, no. 2, hlm. 192, Sep 2018.

[7] M. Mujib, "Mengembangkan Kemampuan Berfikir Kritis Melalui Metode Pembelajaran Improve," $\mathrm{Al}$ Jabar J. Pendidik. Mat., vol. 7, no. 2, hlm. 167-180, Des 2016.

[8] H. Hanif, I. Ibrohim, dan F. Rohman, "Pengembangan Perangkat Pembelajaran Biologi Materi Plantae Berbasis Inkuiri Terbimbing Terintegrasi Nilai Islam Untuk Meningkatkan Pemahaman Konsep Siswa Sma," J. Pendidik. Teori Penelit. Dan Pengemb., vol. 1, no. 11, hlm. 2163-2171, 2016.

[9] P. Sari, "Pemahaman Konsep Matematika Siswa pada Materi Besar Sudut Melalui Pendekatan PMRI," J. Gantang, vol. 2, no. 1, hlm. 41-50, 2017.

[10] E. Yuliasari, "Eksperimentasi model PBL dan model GDL terhadap kemampuan pemecahan masalah matematis ditinjau dari kemandirian belajar," JIPM J. Ilm. Pendidik. Mat., vol. 6, no. 1, hlm. 1-10, 2017.

[11] N. Nursida, "Perbandingan Strategi Pembelajaran Aktif Tipe Topical Review dan Tipe Jeopardy Review terhadap Pemahaman Konsep Matematika Siswa Kelas X SMAN 16 Makassar," diploma, Universitas Islam Negeri Makassar, 2017.

[12] E. Felda, mukhni, dan khairudin, "PENERAPAN STRATEGI PEMBELAJARAN AKTIF TIPE JEOPARDY REVIEW DALAM PEMBELAJARAN MATEMATIKA SISWA KELAS VII SMP NEGERI 7 KERINCI TAHUN PELAJARAN 2013/2014," Abstr. Undergrad. Fac. Educ. Bung Hatta Univ., vol. 4, no. 1, Agu 2014. 
[13] A. Elisa dan W. Syafmen, "Studi Perbandingan Penggunaan Strategi Belajar Aktif Tipe Joepardy Review dan Who Wants To Be A Millionaire Pada Pembelajaran Matematika," EDUMATICA J. Pendidik. Mat., vol. 3, no. $02,2013$.
[14] A. Maedani, "PERBEDAAN HASIL BELAJAR SISWA MENGGUNAKAN STRATEGI BELAJAR AKTIF HOLLYWOOD SQUARES DENGAN PEMBELAJARAN KONVENSIONAL PADA MATA PELAJARAN PENGUKURAN LISTRIK DI SMK NEGERI 5 PADANG," Pendidik. Tek. Elektro, vol. 2, no. 1, Apr 2014. 